\title{
MODELING THE DRIVERS OF LAND USE CHANGE IN ADA COUNTY AND CANYON COUNTY, IDAHO, USING A REGRESSION DISCONTINUITY DESIGN
}

by

Christopher Hans Felt

\author{
A thesis \\ submitted in partial fulfillment of the \\ requirements for the degree of \\ Masters of Arts in Political Science \\ Boise State University
}

May 2017 
(C) 2017

Christopher Hans Felt

ALL RIGHTS RESERVED 
BOISE STATE UNIVERSITY GRADUATE COLLEGE

\title{
DEFENSE COMMITTEE AND FINAL READING APPROVALS
}

\author{
of the thesis submitted by
}

Christopher Hans Felt

Thesis Title: Modeling the Drivers of Land Use Change in Ada County and Canyon County, Idaho, Using a Regression Discontinuity Design

Date of Final Oral Examination: $\quad 01$ March 2017

The following individuals read and discussed the thesis submitted by student Christopher Hans Felt, and they evaluated his presentation and response to questions during the final oral examination. They found that the student passed the final oral examination.

Jeffrey Lyons, PhD. Chair, Supervisory Committee

Michail Fragkias, PhD. Member, Supervisory Committee

Michael Allen, PhD. Member, Supervisory Committee

The final reading approval of the thesis was granted by Jeffrey Lyons, $\mathrm{PhD}$, Chair of the Supervisory Committee. The thesis was approved by the Graduate College. 


\section{DEDICATION}

I dedicate my thesis to my family, friends, and professors. 


\section{ACKNOWLEDGEMENTS}

This research was supported by NSF award number IIA-1301792 from the NSF

Idaho EPSCoR Program and by the National Science Foundation. Its contents are solely the responsibility of the authors and do not necessarily represent the official views of NSF. 


\begin{abstract}
Urbanization and land use change are widespread phenomena and the primary drivers of global ecological change. Researchers from both the social and natural sciences have investigated the effects that land use change has on environmental services and the effectiveness of regulatory bodies in mitigating its harmful impacts. Although there is research on local governmental bodies and their effectiveness in controlling land use change, county governments have often been overlooked. In this article, I study the effectiveness of county governments in controlling land use change using a regression discontinuity design (RDD). The RDD is a quasi-experimental approach that provides stronger support for claims of causality than basic regression analysis. I use the RDD along with multinomial and binary logit estimation to study the capacity of the Ada County government to control land use change in the Treasure Valley, Idaho.
\end{abstract}


TABLE OF CONTENTS

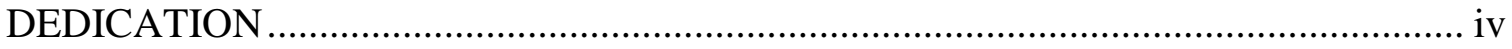

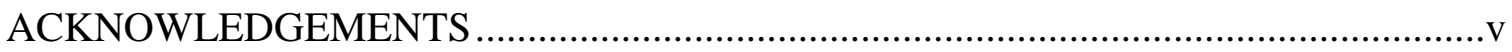

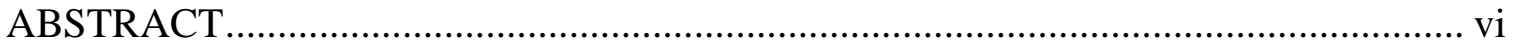

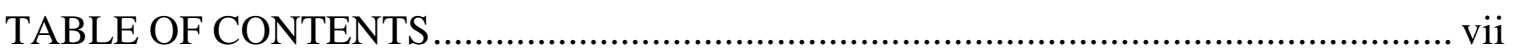

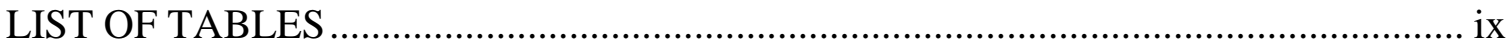

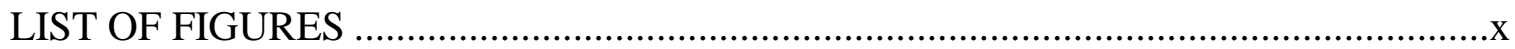

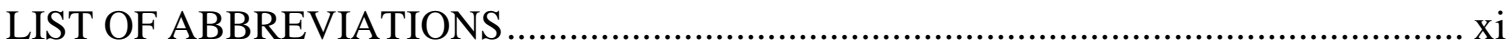

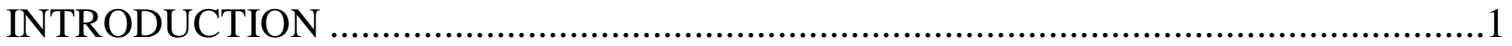

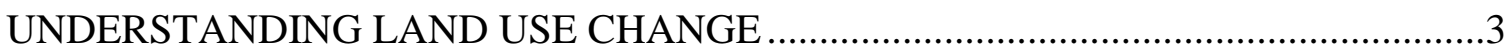

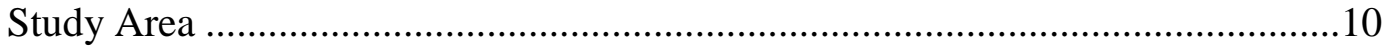

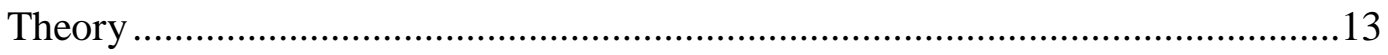

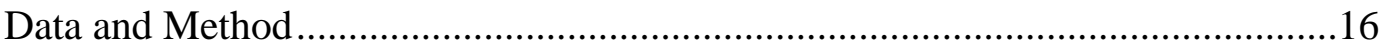

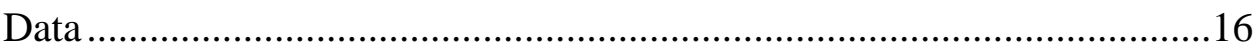

Regression Discontinuity Design...........................................................20

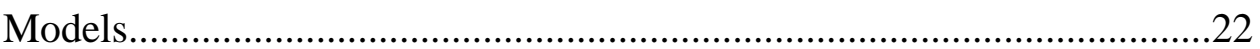

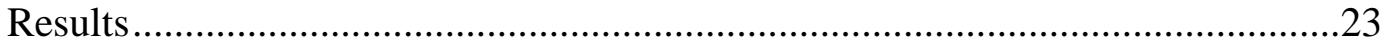

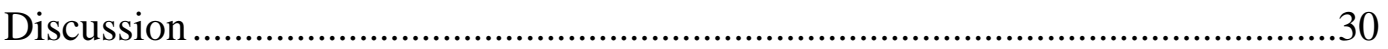

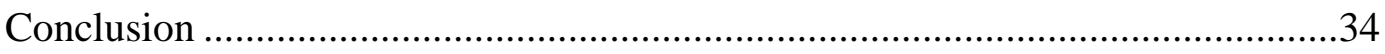

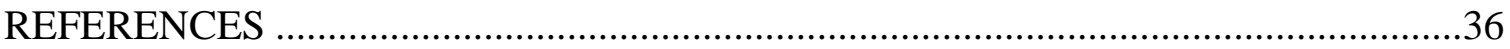




\section{LIST OF TABLES}

Table $1 \quad$ Description of Models and Datasets ………………………………..... 22

Table 2 Results for Multinomial Logit for Period 2001 - 2011 (Model 1) .......... 25

Table 3 Results for Multinomial Logit for Period 2001 - 2006 (Model 2) .......... 27

Table 4 Results for Multinomial Logit for Period 2006 - 2011 (Model 3) ........... 27

Table 5 Marginal Effect for Outcome 1 for All Multinomial Logits (Models 1 - 3)

Table $6 \quad$ Results for Binary Logit for All Periods (Models 4 - 6) ......................... 29

Table $7 \quad$ Marginal Effects for All Binary Logits (Models 4 - 6) ............................ 30

Table $8 \quad$ Correlations of Independent Variables ................................................. 42

Table 9 AS Results for Multinomial Logit including Distance to City and Median

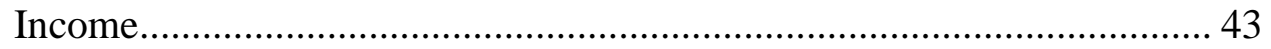

Table 10 AS Results for Multinomial Logit including Distance to Highway and Population Density ................................................................................. 43

Table 11 AS Results for Multinomial Logit including Distance to Highway and Population Density .................................................................................... 44 


\section{LIST OF FIGURES}

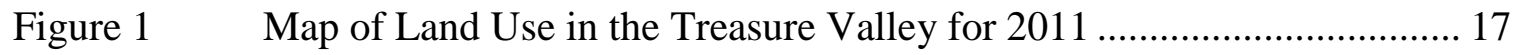

Figure 2 Map of Undeveloped Parcels, RDD, County and City Impact Area

Boundaries .............................................................................. 19 


\section{LIST OF ABBREVIATIONS}

CBD central business district

COMPASS Community Planning Association of Southwestern Idaho

NLCD National Land Cover Database

RDD Regression Discontinuity Design 


\section{INTRODUCTION}

Urbanization and land development are widespread phenomena and the primary drivers of global ecological change (Lewis and Alig 2009). Urbanization can affect ecological systems by altering the pattern of landscapes and land development changes the structure and function of ecosystems. Both have detrimental effects on the provisions and services provided by the ecosystem (Alberti 2005).

The need to understand land development (also referred to as land use change) has prompted research from fields in both the social and natural sciences. Research from economics and political science has developed and improved the theoretical connections between socio-economic factors and land use change (Bockstael and Irwin 2001; Lewis 1996). The field of landscape ecology from the natural sciences has generated a substantial amount of research investigating links between landscape patterns and ecological function.

In addition to improving the understanding of links between environment and land use and land use and humans, numerous researchers study attempts to mitigate and control land use change. These mitigation efforts often take the form of government regulation. The most prominent forms of land use regulation are zoning and adequate facility provision ordinances. Although there are instances of every level of government imposing land use regulation, local government bodies are often those responsible for planning and implementing much of the land use regulation (Bengston, Fletcher and Nelson 2004). There is some research that investigates land use regulation within 
counties (Munroe, Croissant and York 2005; Irwin and Bockstael 2002). However, there are few studies that have focused on the county government (Geohegan and Bockstael 2003: Bockstael 1996) and fewer still that investigate counties that share land use regulation responsibilities with municipalities (Lewis 1996).

In this article, I investigate Ada County as a driver of land use change. In particular, I consider whether a set of land use regulations implemented in Ada County have a discernable effect on land use change. I test for this effect by comparing undeveloped parcels in Ada and Canyon Counties at two levels. The first level considers all undeveloped parcels in both counties. The second level is a subset using the regression discontinuity design (RDD). The RDD takes a subset of a larger sample in which the observations in the subset are nearly matching except for a single variable. The RDD is quasi-experimental in that it attempts to divide the data in such a way that one group of observations act as the control group and the rest as the treated group. The variable that differentiates the group is the treatment variable. This method of resampling the data provides stronger support for claims of causality than basic regression analysis. I then use multinomial and binary logit regression for estimating the effects at the two levels. In the next section, I discuss the relevant literature. The third section describes the study area and explains in more detail the land use regulation implemented in Ada County. The fourth section presents the theory of land use change used in this research and the hypotheses that are tested. The fifth section discusses the data used in the present research, the RDD, and model specifications. The sixth section presents the results. The seventh section gives a discussion of those results. The eighth section concludes the article. 


\section{UNDERSTANDING LAND USE CHANGE}

Land use is defined as the "human employment of land," (Bockstael and Irwin 2001 p. 2). Examples include crop production, grazing, logging and urban development. In defining land use, Bockstael and Irwin (2001) contrast the concept with land cover which is a term that denotes the "physical and biotic characteristics of the surface," (p. 2). Examples of land cover include forest, homogeneous and heterogeneous vegetation, asphalt and ice. The importance of discussing the topics in conjunction with each other is to emphasize the link between human use of land and the subsequent environmental impact. This connection is understood by considering that land cover is the essential determinant of ecological structure and function and land use, to a large extent, determines land cover. Thus, land use becomes important in assessing ecological impacts because it displays the nature of the relationship between humans and the environment.

There are many instances of the human/environment interaction that are captured by the link between land use and land cover. One of the primary links is the discharge of nutrients and toxins generated from specific kinds of land use. For instance, agricultural land use is associated with discharges such as herbicides and pesticides into surface and groundwater and of N20 into the air. Agriculture also erodes the soil and causes salinization of the soil. Urban land use is also associated with discharge into the environment including nutrient and fecal coliforms from sewage and heavy metal from industry and transportation infrastructure. Additionally, the impervious surfaces such as roads and concrete alter hydrological flow which increases soil erosion and aquatic 
habitat deterioration. Defries, Asner, and Houghton (2004) note that humans benefit from land use change because land use change allows for the appropriation of ecosystem goods. However, at the same time, land use change decreases the proportion remaining to perform other ecosystem services. Also, Bockstael and Irwin (2001) state that land use change has an adverse effect on ecosystem services because it alters landscape patterns which affect the movement of nutrients and various species as well as negatively impacting other ecological processes.

This link between land use change and the environment attracted the attention of researchers from many disciplines of which natural scientists have taken the lead and generated a large amount of research (Irwin and Geoghegan 2001; Peterson et al. 2014). Landscape ecology is one field that focuses heavily on the relationship between land use change and landscape patterns and the effects that changes in these patterns have on environmental services. In particular, there is an extensive amount of literature that studies the effects that urbanization has on the environment. Much of this research has found that rapid urbanization is a significant factor in land use change and often leads to the fragmentation of landscape mosaics with detrimental impacts to ecosystem processes (Li et al. 2013). Socio-economic factors are often included into land use change research by natural scientists. However, the method of inclusion has often been atheoretical and has oversimplified the socio-economic phenomenon (Bockstael 1996; Veldcamp and Lambin 2001).

There is a substantial amount of research from economics that has sought to improve the theoretical connection between land use change and socio-economics factors. Two important theories in economics explain land use change: the bid-rent model 
and the optimal timing of development model. Both the bid-rent model and the optimal timing of development model improve the research of land use change by explaining the causal relationship between individual choices and land use outcomes (Irwin and Geoghegan 2001). Early efforts to model land use change used the bid-rent model which was first introduced by von Thunen and subsequently developed by Alonso (1964), Muth (1969) and Mills (1967). The model begins by assuming an urban area is monocentric which means that urban development occurs around a central business district (CBD). This model also assumes that an equilibrium exists between land prices that are declining and transportation cost that are increasing as distance increases from the city center. This exchange between land prices and transportation costs results in economic activity being distributed in concentric rings around the CBD.

Von Thunen hypothesizes that industries that produce products that are time sensitive are located closer to the $\mathrm{CDB}$ to reduce transportation time. Industries in which distance is not a major concern locate at the outer edges of the urban area. Alonso (1964) developed von Thunen's model by substituting farmers and industrialists with residents. Residents make decisions on where to locate based on commuting time to work and the price of housing near the CBD. Alonso's theory expects that if the cost of transportation is low, then residents will choose to locate in subdivision that are farther from the CBD which will encourage the conversion of nonurban parcel to urban. Thus, this theory suggests that land use change is more likely to occur if transportation is relatively inexpensive and residents prefer to live outside of the city.

The more recent literature uses the optimal timing of development model (Carrion-Flores and Irwin 2005; Fragkias and Geoghegan 2010; Irwin and Bockstael 
2002). This model suggests that a landowner's decision to change land use is the selection of the optimal land that maximizes her expected utility. Following from this, the optimal time for a parcel to be developed is when the following two conditions are met. First, the one-time return from selling a parcel or switching its land use, net of conversion costs, exceeds the present value of returns from the current (undeveloped) land use. Second, the rate of increase in net returns is less than the interest rate (i.e. the present value of the net gains from postponing are less than zero). For land use change, this means that the owner of a parcel will change the land use, say from agricultural use to suburban development, when the value of the current land use is less than the alternative and the cost of waiting to change the land use outweighs the benefit of waiting. In the context of zoning and other land use regulation, land use change is expected to be less likely to occur in areas where development is prohibited. It is less likely because land use regulation increases the cost to develop the parcel.

The previous theories focus on a single individual's decision (either a developer or a land owner) to explain land use change, however, these theories neglect other actors in the land use change process as well as the institutions in which these actors interact. There are some theories in political science that address this absence. For instance, Lewis (1996) applies a method of analysis that he refers to as "institutional analysis." Lewis explains that land use change is the result of land developers, parochial elites, elected officials and residents interacting within various institutions. The institutions of interest are those that have some degree of control over land use policy. The amount of land use change in a given area is dependent upon the degree of political fragmentation, a function of the number of local government bodies that are responsible for land use policy. Areas 
that have several local governments are considered highly fragmented and those with fewer are not. Lewis explains that the degree of political fragmentation that exist between local government bodies is correlated with the amount of land use change that occurs. Higher amounts of land use change are linked to higher degrees of political fragmentation because political fragmentation implies a diversity of land use policies and enforcement practices among government bodies. If a local government must compete for new residents and developers, it is less inclined to be stringent with its land use policy, thus weakening control over land use change.

To counter the detrimental effects that land use change has on the environment, policies are implemented to control the amount and kind of change that can occur. Bockstael and Irwin (2001) explain that policies to control land use are primarily concerned with controlling urban sprawl that is the result of unregulated land use change. Policies to discourage urban sprawl include increasing minimum lot sizes required for development, charging impact fees, or withholding public utility provisions. Bengston, Fletcher and Nelson (2004), classifies these policies into three categories: public acquisition, incentives and regulation. Public acquisition is often used to protect open space and examples include public ownership of parks, recreation areas and green belts. Incentives often take a monetary form and can discourage development by increasing the cost to developers in a certain area by charging impact fees or development taxes.

In the U.S., these policies are largely implemented at the scale of local government and are directed at the incentives faced by the individual land owners (Bockstael and Irwin 2001). Although land use policies are implemented at all levels of government, regulatory tools are more often used at the local level, one of the core tools 
is zoning (Bengston, Fletcher and Nelson 2004). In many cases, zoning is used to prohibit low intensity development that is characteristic of urban sprawl. The research on zoning is extensive (Butsic, Lewis and Ludwig 2011), however, its effects on urban growth are inconclusive. Some research has found that zoning affects the amount and type of land use that occurs (Munroe, Croissant and York 2005). While others have found the use of zoning regulations to be an endogenous factor of land use change (Butsic, Lewis and Ludwig 2011) or a contributing factor to urban sprawl (Levine 2006).

In addition to zoning, adequate public facilities ordinances are another tool in the local government regulatory toolbox that allows a government to temporarily deny development to occur within that government's jurisdiction. These laws control development by setting capacity limits on such things as schools or transportation networks. For instance, if the school or transportation network is set at a capacity in which more development would lead to an excess of that capacity, then development in that area is prohibited (Fragkias and Geoghegan 2010). As with zoning, however, the effectiveness of these regulatory tools is inconclusive. One reason adequate public facilities ordinances are ineffective is due to local government leniency in giving exceptions to developers in the form of waivers or paying additional fees (Geoghegan and Bockstael 2003).

Although there has been research on the relationship between local government bodies and land use change, few have tried to tease out the effect that county governments have on land use change. That is not to say that counties are not included within many land use studies. Rather, county governments are often not included as a driver of land use change or are not differentiated from other local government bodies 
such as cities or special districts. Often, if the county is included within a study it will be to demarcate a study area. For instance, Carrion-Flores and Irwin (2004) use Medina County, Ohio county lines to designate their study area. In their research, they examine effects that city zoning ordinances within the county have on rural land conversion. Exceptions included instances in which the county location of a parcel is included within a specification. For example, Bockstael (1996) examines parcels that are located within the Patuxent watershed (near Washington D.C.). In this study, the county variables are found to be significant. However, this study did not specify which policies are implemented at the county level. One study does focus on the effects of land use policy at the level of county governments and its effect on land use change. Geoghegan and Bockstael (2003) examine land use change in counties that surround Washington, D. C. In their study, each county implements a series of adequate public facilities ordinances and of the three counties, only two counties are effective in controlling land use change.

Although the research on counties exists, the results from these studies cannot be generalized. Lewis (1996) explains that counties differ in terms of power over land use policy. Lewis identifies two major patterns of scope and organization of power over land use policy. The first pattern is a strong metropolitan county with a single large city with few or no smaller municipalities. The second pattern is a county with strong land-use powers in unincorporated areas, but little power within the several incorporated municipalities. According to Lewis, the latter pattern is the typical pattern in the mid and far west and south Atlantic regions of the US. In the previous research, it is not clear what kind of pattern the study areas exhibit because the counties in the study are tucked in between Baltimore and Washington D.C., two major cities. Additionally, the authors 
do not specify what the scope of the power is for the counties in relation to the other, smaller municipalities in the area. If it is the case as Lewis suggests that there are two patterns of scope and organization of power over land use policy and that this type of pattern is typical of urban areas in certain parts of the U.S., then it is important to test the effectiveness of county governments in these areas.

Also, the previous literature often uses various forms of regression analysis including ordinary least squares and maximum likelihood estimation formulations. However, these methods can only support association inferences and are inadequate in supporting inferences of causality (Freedman 1991). This inadequacy stems from the research design and the present research overcomes this flaw by using an RDD. The RDD is a quasi-experimental design that improves the ability of statistical methods in supporting causal inferences. This research design is discussed in more detail in the Data and Method section.

\section{Study Area}

One place that offers an opportunity to test the effectiveness of land use policy on land use change across counties is the Boise metropolitan area (also referred to as the Treasure Valley) in Idaho for the period from 2001 to 2011. The Treasure Valley provides an opportunity for several reasons. First, it fits Lewis's (1996) second pattern of scope and arrangement of county and municipal government control of land use change policy. The Boise metropolitan area spans two counties: Ada and Canyon. Each county contains several cities with each responsible for land use planning within its jurisdiction and county governments responsible for any remaining unincorporated areas.

Additionally, the Treasure Valley is a site of a substantial amount of land use change and 
population growth. For instance, three of the largest cities in the state (Boise, Nampa, and Meridian) and much of the urban development that is occurring within the state is in the Treasure Valley for the period from 2001 to 2011 (Dahal, Benner and Lindquist 2017). Also, during this same period, the population in the Treasure Valley increased by 32 percent (US Census 2014).

Another reason that the Treasure Valley offers an excellent opportunity for studying land use change policy is the possibility of a natural experiment that it presents. The two counties in the Boise metropolitan area had differing approaches to land use policy. Ada County was more active in planning during the period from 2001 to 2011, while Canyon County was much less involved with planning leaving much of the responsibilities to the cities. In particular, in 2006 Ada County adopted and began implementing land use policies contained within the plan called "Blueprint for Good Growth" (Brawer and Vespa 2008, hence forth "Blueprint").

The Blueprint is a "collaborative multi-jurisdictional effort intended to coordinate land use and public facility decisions so that growth in Ada County will be an asset to existing residents and future generations," (pg. 1, Planning Works \& Paul et al. 2006). The local government bodies that are part of the collaborative effort are Ada County, the cities within Ada County, Ada County Highway District and the Community Planning Association of Southwestern Idaho (COMPASS) which is a non-profit planning association for the Treasure Valley. The Blueprint builds upon and incorporates previous planning efforts. For instance, the framework of the Blueprint builds upon a land use and transportation guide plan commissioned by the Ada County Highway District (Planning 
Works and Paul et al. 2006). Additionally, the Blueprint incorporates some aspects of the "Communities in Motion" long term transportation plan developed by COMPASS. Blueprint development began in mid-2004 and started with the formation of a steering committee that consisted of stakeholders ranging from government officials from the local city governments to developers and major employers in the Treasure Valley. The government officials along with members from the Ada County Highway District and COMPASS held voting power in these committees. The process of development started with focus group and community meetings with various groups of stakeholders in the local community. In 2005, the focus of development shifted to the incorporation of aspects of the Communities in Motion long term transportation plan. Also, during this time, the steering committee held occasional consortium business meetings where plans for the Blueprint were submitted and feedback was received from attendees. Towards the end of 2005 and the beginning of 2006, the steering committee started incorporating aspects of the plan commission by the Ada County Highway District (Blueprint for Good Growth 2017).

The Blueprint is broken into two phases (Brawer and Vespa 2008). The first phase establishes goals and policies for sustainable development that are to be incorporated into the comprehensive plans of the cities within Ada County as well as the county itself (Planning Works LLC and Paul et al. 2006). There are several policies that are directed at controlling land use change. The first set of policies are meant to control urban development within city impact areas. Impact areas indicate where public facilities are to be available in the future. Another set of policies are directed at maintaining and protecting rural land. These policies set limits on the amount of rural land that can be 
developed. There are also policies that are meant to establish equity based programs which protect open space. The anticipated date of completion of Phase I ranged from November 2005 to March 2006.

Phase II of the Blueprint involves the implementation of the plan using regulatory tools including adequate public facility ordinances and zoning (Brawer and Vespa, 2008). Although there are many policies set up to curb sprawl and encourage high density development, the Blueprint allows Ada County and the cities within it to permit development within its jurisdiction but not in its impact area. However, the Blueprint requires the development to be annexed by one of cities or the county. In 2007, Ada County incorporated the elements of the Blueprint related to increases of urban development to be confined to impact areas and restricting urban development in rural and unincorporated areas into its comprehensive plan for future development (Ada County Comprehensive Plan 2007). In the comprehensive plan, Ada County effects land use change through zoning regulations and working with cities to encourage development within designated impact areas. Boise is the only other Ada County local government body to update and incorporate aspects of the Blueprint into its comprehensive plan before 2011 (Brawer and Vespa, 2008).

\section{Theory}

The research in this paper follows the recent economic literature in explaining land use change using the optimal timing of development model. This theory suggests that developers will decide to change the land use of their parcel if doing so increases their utility over the current land use. Additionally, they will change land use at the present time if the cost of waiting outweighs future gains. 
In the context of the Treasure Valley, there are two theorized outcomes for the developers' decision to change the land use of a parcel. Each outcome relates to a set of Blueprint policies adopted and implemented by Ada County in its comprehensive plan. The first set of policies are those that pertain to the restriction of development in unincorporated and rural areas. The second set of policies are those that pertain to increases in urban development and contain those increases within impact areas. Finally, these policies took effect in 2007 which means that the policies should produce an effect for the period from 2006 to 2011. Given these two sets of policies the first hypothesized outcome is as follows:

Hypothesis 1: If a parcel is located in Ada County then the parcel is less likely to change land use from undeveloped land use to a developed land use than a parcel located in Canyon County.

In terms of the individual developer or landowner, this hypothesis suggests that the parcel will be less likely to change within Ada County because it will increase the cost to develop the parcel. For instance, assume that there are two land owners who each own a parcel. One land owner is located in Ada County and the other is located in Canyon County. Also assume that there is a developer who wants to purchase a parcel and then develop it. The first hypothesis suggests that Ada County will impose an additional cost on developing a parcel in Ada County. This additional cost will reduce the amount that the developer can offer to purchase the parcel from the Ada County land owner which will reduce the likelihood that the land owner will sell the parcel. Thus, the 
developer is encouraged to go to the Canyon County land owner in which the additional cost is removed and then offer a higher amount to purchase that owner's parcel which will increase the likelihood that the owner will sell the parcel. This outcome means that parcels in Canyon County are more likely to be developed than parcels in Ada County. In terms of estimation, the dummy variable captures the county location of a parcel and an observation is given the value of 1 if it is located in Ada County. I expect the coefficient for that variable to be negative. This result means that a parcel is more likely to change land use from undeveloped to developed in Canyon County. This does not mean that I do not expect development to occur in Ada County. Rather, if development occurs, it will occur in areas that are already urbanized. However, if it is the case that a parcel is more likely to develop if it is located in Ada County, then the alternative hypothesized outcome is as follows:

Hypothesis 2: If a parcel is located in Ada County, then it is more likely to change land use from undeveloped to a developed land use if it is located within a designated city impact area.

Referring to the individual developer and land owner again, the second hypothesis suggests an outcome similar to the first hypothesis. Instead of land owners from separate counties, the developer is faced with a land owner who is located in the unincorporated area and a land owner located in a city impact area. Since Ada County is discouraging development in the unincorporated area and encouraging development in the city impact areas, there is an additional cost to develop the unincorporated area and not in the city 
impact area. Given this additional cost, the developer will be able to offer more to land owners located within the impact area than land owner in the unincorporated area. Therefore, the parcel owner located in the impact area is more likely to sell than the parcel owner in the unincorporated area. This outcome means that parcels located in city impact areas are more likely to develop than parcels located in the unincorporated areas.

In terms of estimation, including the dummy variable indicating county location and an additional variable that indicates whether a parcel is located within a city impact area (observation $=1$ if it is in an impact area), I expect the coefficient for both to be positive. The coefficients will both be positive because if a parcel is more likely to develop in an impact area then it is more likely to develop within Ada County since the impact areas are in Ada County. But I expect the city impact area to have a larger effect than the county variable. These results mean that a parcel located in Ada County is more likely to change land use from undeveloped to developed if it is located in a city impact area. The next section explains the data and method used to test these hypotheses.

\section{Data and Method}

$\underline{\text { Data }}$

The datasets for the analysis are constructed using three sets of data: National Land Cover Database (NLCD) (Fry et al. 2011; Homer et al. 2007; Homer et al. 2015) land cover layers, shapefiles generated and collected by COMPASS and TIGER shape files from the US Census (US Census 2015). Combining these data sources generates a dataset of geographic, demographic and land use information for parcels in the Treasure Valley. This information includes distance to geographic features such as water bodies and city centers. It also includes information such as population density and land use type 
for multiple years. The observations in the entire dataset are 88,893 parcels that are undeveloped as of 2001 and are located within Ada County and Canyon County.

There are a total of six dependent variables each indicating whether a parcel changed land use. The dependent variables cover three different periods: 2001 to 2011, 2001 to 2006,2006 to 2011 . For each period there is a binary and categorical version. The values for the dependent variables capture change from all types of undeveloped land use (agriculture, desert, shrub, forest, etc.) as a single type of land use (undeveloped) to the three forms of developed land use: low, medium and high. Figure 1 shows a map of the land use in the Treasure Valley for the year 2011.

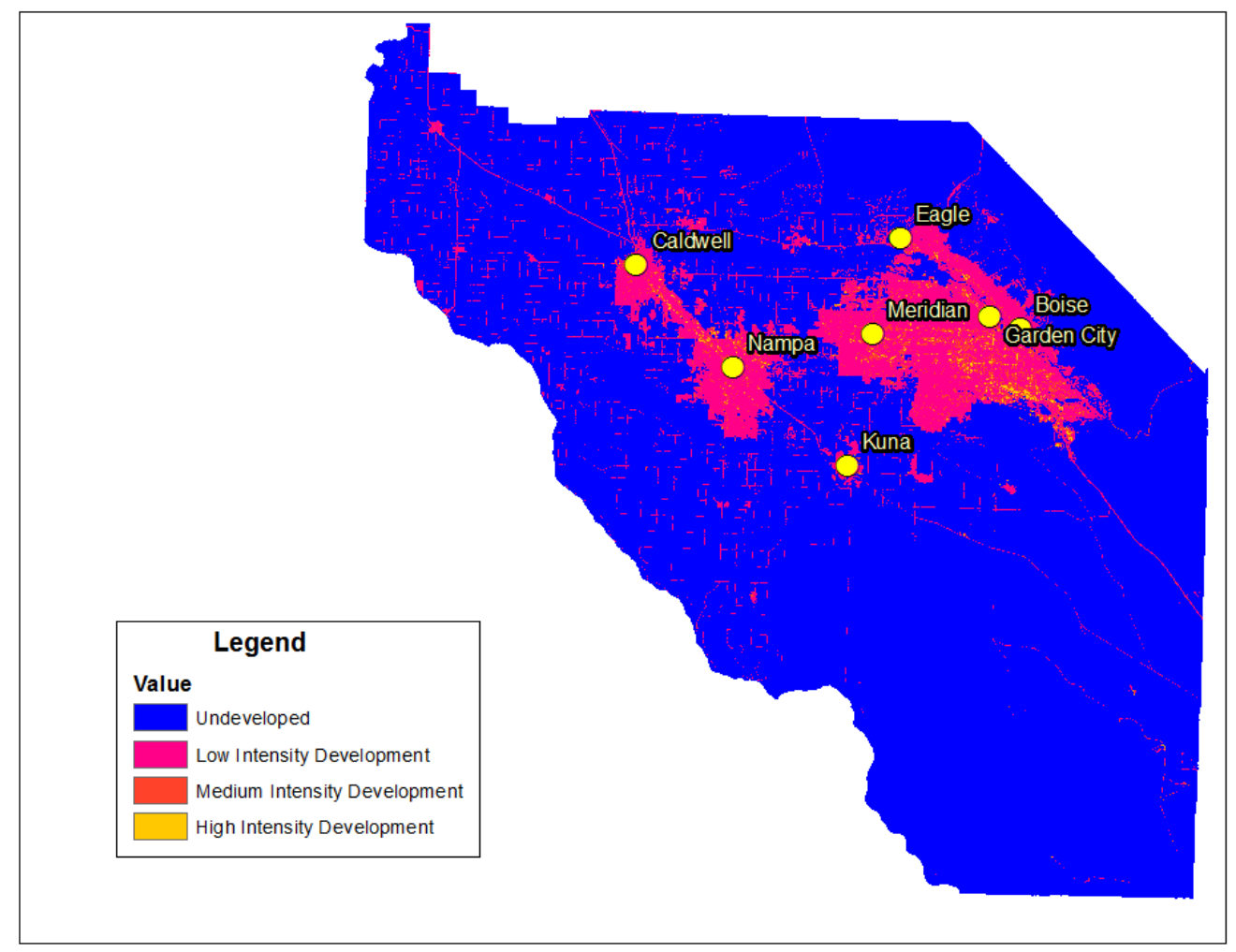

Figure 1 Map of Land Use in the Treasure Valley for 2011 
The binary version the dependent variable captures whether a parcel changes land use from undeveloped to a developed form of land use. The outcomes for the binary dependent variables are either 0 or 1 . A parcel assigned the value of 1 indicates that the parcel has changed land use from undeveloped to developed.

The categorical version of the dependent variable captures whether a parcel changed from undeveloped to a specific developed land use form. The categorical version has four outcomes: 0 for no change, 1 for undeveloped to low intensity development, 2 for undeveloped to medium intensity development, 3 for undeveloped to high intensity development. Thus, there are a total of six dependent variables including a binary and categorical version for each period.

The reason for including both a binary and categorical dependent variable is the small number of occurrences of Outcomes 2 and 3 in the RDD datasets discussed below. Thus, the outcomes are combined as a single outcome (developed). For the years 2001, 2006, and 2011, the dependent variables are generated using the NLCD layers, parcel shapefiles, ArcMap and Geospatial Modeling Environment software packages to calculate the land use for each year for each parcel.

The independent variables are generated using shapefiles from COMPASS, TIGER, and ArcMap functionality. The primary variables of interest are the county variable and the impact area variable (Figure 2). The county variable is the treatment variable which is another important aspect of the RDD. The county variable is a dummy variable that captures whether a parcel is located within Ada and Canyon Counties. If the parcel is located in Ada County, then the parcel receives the value of 1. The impact area variable captures whether a parcel is located within a city impact area within Ada 
County. If the parcel is located within an impact area, then the parcel receives the value of 1. Given that aspects of the Blueprint, such as the encouragement of development within impact areas, are implemented after 2006 the impact area variable is only included in the models that examine the period from 2006 to 2011.

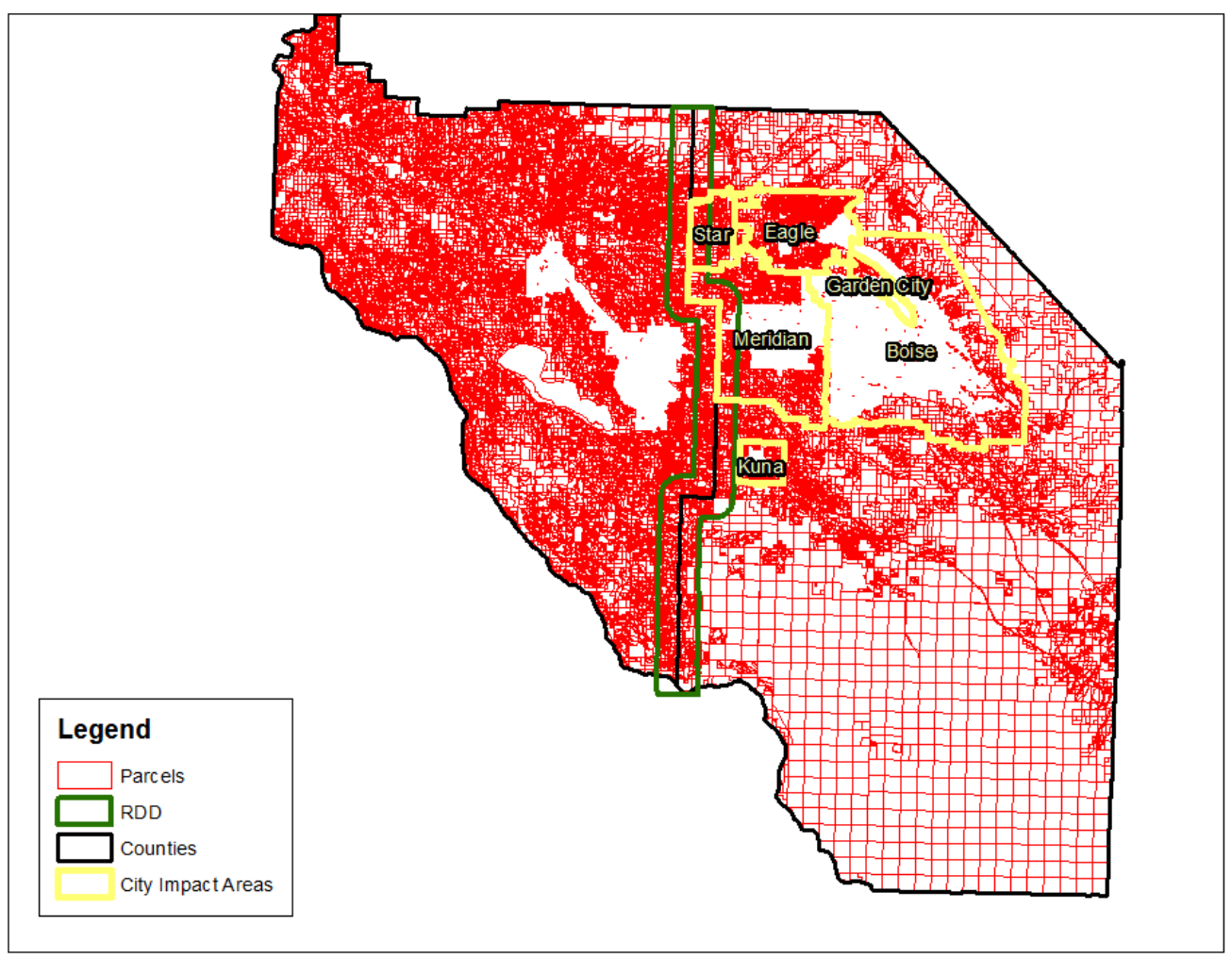

Figure 2 Map of Undeveloped Parcels, RDD, County and City Impact Area Boundaries

The remaining independent variables are meant to capture other factors that contribute to land use change. The first two independent variables measure the distance a parcel is from certain features. The first variable captures the distance to the nearest city. The second variable is distance to water features. The water features that are included 
within the calculation of this variable is the Boise River, Snake River and Lake Lowell. The remaining variables include parcel size and variables for demographic characteristics. The parcel size of each parcel is measured in acres and is then transformed into its logarithmic form. The demographic variable that is used is population density which is calculated at the block group level.

\section{$\underline{\text { Regression Discontinuity Design }}$}

In examining land use change in the Treasure Valley, I will be following the literature by using two forms of the logistic regression (Carrion-Flores and Irwin 2005; Fragkias and Geoghegan 2010; Bockstael 1996). However, regression analysis is brought into question by many for its inability to prove causality (Freedman 1991; Berk 1991; Blalock 1991). Several reasons are given but the reason that is important for the present research is that social science researchers can never observe the outcome of both treatment and control on the same unit of observation. The issues that plague regression analysis is especially true in spatial analysis where variables tend to be correlated over space (Geoghegan and Bockstael 2003). For instance, the estimated probability of a parcel changing land use may be affected by being near or far away from other parcels or geographic features.

To circumvent the issues with proving causality that comes with using regression analysis, some researchers have adopted an RDD (Lee and Lemieux, 2010). An RDD overcomes the issue of regression analysis because it is a quasi-experimental design. That is, the observations in a given dataset are nearly matching except by a single variable which indicates whether or not an observation has a certain quality. This difference in a single quality allows the dataset to be separated into two groups: a control group and 
treated group. The single differentiating variable is the treatment. Thistlethwaite and Campbell (1960) pioneered the research design and demonstrate it by collecting information on a group of students who are near winners of a national scholarship competition. The subjects match on several background variables except for one which acted as the treatment variable. The treatment variable is the receipt of a certificate of merit and subsequent public recognition. Thistlethwaite and Campbell hypothesize that the outcome from receiving the award and the subsequent public recognition encourages students to pursue intellectually oriented careers.

Although Thistlethwaite and Campbell's results ultimately do not support their hypothesis, RDDs are utilized in land use change research. For instance, Carrion-Flores and Irwin (2005) use an RDD to observe land use change in which the observations are parcels that change land use and the treatment variable is the application of a minimum lot size zoning ordinances on those parcels. To guarantee that the observations are nearly matching, Carrion-Flores and Irwin choose parcels that are within 2500 feet of the zoning boundary in Medina County. Then, to capture the effect that zoning has on the parcel's land use change, a dummy variable that records whether a parcel fell within or outside of the zoning boundary is included within their model which is estimated using a logistic regression. The magnitude of the variable is an indication of the effect that the zoning boundary has on the parcel changing land use. Thus, to improve the strength of my results in supporting causal claims, I implement an RDD.

To employ an RDD, a subset of the dataset of parcels are chosen to guarantee that the observations are closely matching in several respects. The present research follows the previous research in creating a subset to utilize an RDD (Carrion-Flores and Irwin 
2005, Grout, Jaeger and Plantinga 2011). In previous research, a maximum distance of two miles from the boundary of interest is used to create a subset to utilize the benefits of an RDD. In the present research, the subset includes only those parcels that are within 1 mile of the Ada County and Canyon County border as shown in Figure 2. This distance falls within the range of distances used by previous research. In addition to an RDD subset, the analysis also uses three more subsets. The first subset includes all parcels for the entire Treasure Valley that are undeveloped in 2001. The last two datasets are subsets of the previous datasets and include only parcels that are undeveloped as of 2006. Table 1 includes description of each dataset.

$\underline{\text { Models }}$

Table 1 gives a description of each model. There are six models and each model captures a different aspect of the landscape of changing parcels.

\section{Table 1 Description of Models and Datasets}

\begin{tabular}{|c|c|c|c|c|c|c|c|c|}
\hline Models & $\begin{array}{l}\text { DV } \\
\text { Version }\end{array}$ & Dataset & $\begin{array}{l}\text { \# of } \\
\text { parcels }\end{array}$ & $\begin{array}{l}\text { Outcome } \\
\text { 0 }\end{array}$ & $\begin{array}{l}\text { Outcome } \\
1\end{array}$ & $\begin{array}{l}\text { Outcome } \\
2\end{array}$ & $\begin{array}{l}\text { Outcome } \\
\mathbf{3}\end{array}$ & $\begin{array}{l}\% \\
\text { change }\end{array}$ \\
\hline Model 1 & Categorical & 2001 & 88893 & 66516 & 20011 & 2337 & 79 & $25 \%$ \\
\hline Model 2 & Categorical & 2001 & 88893 & 67419 & 19351 & 2112 & 61 & $24 \%$ \\
\hline Model 3 & Categorical & 2006 & 67434 & 66502 & 910 & 19 & 3 & $1 \%$ \\
\hline Model 4 & Binary & $\begin{array}{l}\text { RDD, } \\
2001\end{array}$ & 7821 & 6369 & 1452 & - & - & $19 \%$ \\
\hline Model 5 & Binary & $\begin{array}{l}\text { RDD, } \\
2001\end{array}$ & 7821 & 6369 & 1427 & - & - & $19 \%$ \\
\hline Model 6 & Binary & $\begin{array}{l}\text { RDD, } \\
2006\end{array}$ & 6369 & 6344 & 25 & - & - & $0.4 \%$ \\
\hline
\end{tabular}

Models $1-3$ use the categorical dependent variable. These models capture the effects that the independent variables have on parcels changing land use from undeveloped to various forms of development. Models $4-6$ use the binary variable and capture the effects that the independent variables have on land use change from undeveloped to developed. The models also differ on time periods and associated datasets. For instance, 
Models 1 and 4 use the dependent variable that examines the period from $2001-2011$.

For Model 1, the entire dataset is used in the estimation. Model 4 uses a subset that

utilizes the RDD. Models 1 and 4 are meant to capture the overall effect that the

independent variables have on the dependent variables for the entire period. Models 2 and

5 use the same datasets as Models 1 and 4, respectively, and use the dependent variable

that spans the period from 2001 - 2006. Models 2 and 5 are meant to capture a baseline

effect that the drivers have on the dependent variables. These models act as a baseline

because they estimate the effects during the period before the Blueprint is implemented.

Models 3 and 6 use subsets of those used by Models 1 and 4, respectively. Both subsets

include only parcels that are undeveloped as of 2006. Each model uses all the

independent variables introduced in the previous section with the exception of the impact

area variable. ${ }^{1}$ The models are estimated with one of the following methods: multinomial

logit and binary logit. Models $1-3$ use the multinomial logit and Model $4-6$ use the

binary logit. $^{2}$

\section{Results}

The results for this analysis are included in Tables $1-7$. Table 1 describes the models and associated datasets. Table $2-4$ shows the results for the multinomial logit estimation of Models $1-3$. Table 5 shows the marginal effects for Outcome 1 for each model. This outcome is the only outcome included in the analysis. The coefficients for other outcomes for each model are insignificant. Table 6 shows the results for the binary

1 Other specifications are tested that included additional independent variables. However, these specifications suffered from multicollinearity. Thus, the reduced specification is adopted in the present research. A correlation table and estimation results for the alternative specifications are included in Appendix 1.

2 Models $1-3$ are also estimated using an ordinal logit. However, the results were not included because the coefficients from each model violate the parallel regression assumption. 
logit estimation of models $4-6$. Table 7 shows the marginal effects for the logit estimations.

Table 1 shows the characteristics of each model. The table shows the number of parcels in each dataset as well as the percentage of those parcel that change land use. The datasets for the first models include parcels from across both counties. The dataset for Models 1 and 2 include 88893 parcels. For Model 1's dataset, 25 percent of those parcels change land use. For Model 2's dataset, 24 percent of the parcels change land use. The dataset for Model 3 includes 67, 434 parcels with 1 percent of the parcels changing land use which is a substantial decrease from the dataset for the two previous models. Models 4- 6 use datasets based on the RDD. For Models 4 and 5, the number of parcels for their associated datasets are 7821 with 19 percent and 18 percent of the parcels changing land use, respectively. For model 6, there are 6369 parcels in the dataset with 0.4 percent changing land use. As with the difference between the datasets for Models 1, 2 and 3, the difference in the number of parcels between the datasets for Model 4 and 5 and the dataset for Model 6 is substantial. For instance, 18 percent of the parcels change land use in the dataset used by Model 5 whereas only 0.4 percent change in the dataset used by Model 6.

The multinomial logit estimations for Model 1 are included within Table 2. The results show the effects that the independent variables have on land use change from 2001 - 2011 using the categorical variable. All of the variables are significant for all outcomes with the exception of the distance to water feature variable. This variable is insignificant for undeveloped to high intensity development (Outcome 3). For those variables that are significant, they are all in the same direction for each outcome. These 
results suggest that a parcel is likely to change land use from undeveloped to development of any form if it is located within Ada County. Additionally, the parcel is likely to change land use if it is small, near the city and in an area with high population density. Parcels that change land use from undeveloped to low or medium intensity (Outcome 1 and Outcome 2, respectively) are more likely to do so the farther away they are from a water feature. This result is contrary to the result for land use change from undeveloped to high intensity development in which case, as distance increases from a water feature a parcel is less likely to change land use. However, this result is insignificant.

Table 2 Results for Multinomial Logit for Period 2001 - 2011 (Model 1)

\begin{tabular}{|c|c|c|c|c|c|c|}
\hline \multirow[t]{2}{*}{ Outcomes (Base: 0) } & \multicolumn{2}{|l|}{1} & \multicolumn{2}{|c|}{2} & \multicolumn{2}{|l|}{3} \\
\hline & $\beta$ & sig & $\beta$ & sig & $\beta$ & sig \\
\hline County $^{\wedge}$ & 0.815805 & $* * *$ & 1.446398 & $* * *$ & 1.539145 & $* * *$ \\
\hline Impact Area $^{\wedge}$ & - & - & - & - & - & - \\
\hline Parcel Size & -0.46168 & $* * *$ & -0.53087 & $* * *$ & -0.50716 & $* * *$ \\
\hline Distance to Nearest City & $-5.3 \mathrm{E}-05$ & $* * *$ & $-7.2 \mathrm{E}-05$ & $* * *$ & $-7.6 \mathrm{E}-05$ & $* * *$ \\
\hline Distance to Water Feature & $7.60 \mathrm{E}-06$ & $* * *$ & $9.36 \mathrm{E}-06$ & $* * *$ & $-2.94 \mathrm{E}-06$ & - \\
\hline Pop. Density & 0.001223 & $* * *$ & 0.000875 & $* * *$ & 0.000744 & $* *$ \\
\hline Constant & -0.91458 & $* * *$ & -3.06694 & $* * *$ & -6.15802 & $* * *$ \\
\hline Pseudo R2 & 0.28 & & & & & \\
\hline $\mathrm{N}$ & 88893 & & & & & \\
\hline$* * *=$ Significant at $1 \%$ & $* *=$ Signific & nt at $5 \%$ & $*=$ Signific & t at $10 \%$ & ${ }^{\wedge}=$ Dummy & riable \\
\hline
\end{tabular}

Table 3 and Table 4 show the multinomial logit estimations for Models 2 and 3, respectfully. Model 2 captures land use change from 2001 to 2006, the time period before the Blueprint is implemented. Model 2 captures the effect that the drivers have on land use change before policy is implemented. Model 3 captures land use change from 2006 to 2011 which is the period when the Blueprint was implemented. The results for Models 2 and 3 are very similar to the results for Model 1 in terms of direction of coefficient for 
each outcome. There is only one difference between the results for Models 1 and 2. This difference consists of the significance of the distance to water feature variable for Outcome 3. In Model 2 the coefficient is significant whereas in Model 1 it is insignificant. However, the direction of the coefficient remains the same. The directions of the coefficients for Model 3 largely match those of Models 1 and 2, however, many of them are insignificant. For instance, many of the results for the primary variables of interest are insignificant. For the county variable, the coefficient for Outcome 1 is positive and significant. This indicates that if a parcel is located in Ada County it is more likely to change land use. The results for the remaining outcomes are negative but insignificant. The results for the impact area are negative for Outcomes 1 and 3 and positive for Outcome 2. However, none of the results for the impact area variable are significant. Of the remaining independent variables, there are only two that are significant across all outcomes for Model 3. The first is distance to nearest city. The coefficient for this variables is negative across all outcomes. This result suggests that as distance from the nearest city increases each type of development is less likely to occur. This result matches the results for the other models. The other variable that is significant is the distance to water feature which is positive for all outcomes. This result differs from the results for Outcome 3 in the previous models. The results for the previous models suggest that as distance from a water feature increases, land use change from undeveloped to high density development is less likely to happen. However, this result is contrary to the result for Outcome 3 in Model 3. 
Table 3 Results for Multinomial Logit for Period 2001 - 2006 (Model 2)

\begin{tabular}{|c|c|c|c|c|c|c|}
\hline \multirow[t]{2}{*}{ Outcomes (Base: 0) } & \multicolumn{2}{|l|}{1} & \multicolumn{2}{|l|}{2} & \multicolumn{2}{|l|}{3} \\
\hline & $\beta$ & $\operatorname{sig}$ & $\beta$ & $\operatorname{sig}$ & $\beta$ & sig \\
\hline County $^{\wedge}$ & 0.815424 & $* * *$ & 1.373079 & $* * *$ & 1.693372 & $* * *$ \\
\hline Impact Area $^{\wedge}$ & - & - & - & - & - & - \\
\hline Parcel Size & -0.44908 & $* * *$ & -0.5361 & $* * *$ & -0.37267 & $* * *$ \\
\hline Distance to Nearest City & $-5.2 \mathrm{E}-05$ & $* * *$ & $-7 E-05$ & $* * *$ & $-6.8 \mathrm{E}-05$ & $* * *$ \\
\hline Distance to Water Feature & 7.38E-06 & $* * *$ & $1.01 \mathrm{E}-05$ & $* * *$ & $-1.9 \mathrm{E}-05$ & $* * *$ \\
\hline Pop. Density & 0.001205 & $* * *$ & 0.000836 & $* * *$ & 0.001111 & $* * *$ \\
\hline Constant & -1.00878 & $* * *$ & -3.21854 & $* * *$ & -6.52889 & $* * *$ \\
\hline Pseudo R2 & 0.27 & & & & & \\
\hline $\mathrm{N}$ & 88893 & & & & & \\
\hline$* * *=$ Significant at $1 \%$ & $* *=$ Signifi & ant at $5 \%$ & $*=$ Signific & th at $10 \%$ & $\wedge=$ Dumm & Jariable \\
\hline
\end{tabular}

Table 4 Results for Multinomial Logit for Period 2006 - 2011 (Model 3)

\begin{tabular}{|c|c|c|c|c|c|c|}
\hline \multirow[t]{2}{*}{ Outcomes (Base: 0) } & \multicolumn{2}{|l|}{1} & \multicolumn{2}{|l|}{2} & \multicolumn{2}{|l|}{3} \\
\hline & $\beta$ & $\operatorname{sig}$ & $\beta$ & sig & $\beta$ & sig \\
\hline County $^{\wedge}$ & 0.70998 & $* * *$ & -3.76424 & - & -13.2923 & - \\
\hline Impact Area^ ${ }^{\wedge}$ & -0.14089 & - & 5.058124 & - & -1.5792 & - \\
\hline Parcel Size & -0.22421 & $* * *$ & -0.04934 & - & -0.2161 & - \\
\hline Distance to Nearest City & $-6.5 \mathrm{E}-05$ & $* * *$ & $-5 \mathrm{E}-05$ & $* *$ & -0.00027 & $*$ \\
\hline Distance to Water Feature & 7.39E-06 & $* * *$ & 3.33E-05 & $* *$ & 0.000189 & $* *$ \\
\hline Pop. Density & 0.000294 & $* * *$ & 0.001072 & $*$ & -0.00158 & - \\
\hline Constant & -3.03271 & $* * *$ & -8.24471 & - & -7.15945 & - \\
\hline Pseudo R2 & 0.14 & & & & & \\
\hline $\mathrm{N}$ & 67434 & & & & & \\
\hline$* * *=$ Significant at $1 \%$ & $* *=$ Signific & at at $5 \%$ & $*=$ Significar & at $10 \%$ & $\wedge=$ Dummy & ariable \\
\hline
\end{tabular}

The marginal effects for the first outcome for Models 1 - 3 are included in Table

5. The coefficients for the marginal effects for each model are significant with the exception of the impact area variable in Model 3. Additionally, the marginal effects for Model 3 are much smaller than those for Models 1 and 2. For instance, if a parcel is located in Ada County from 2001 - 2006 it is 8 percent more likely to change land use 
than a parcel in Canyon County. This results shrinks to 0.3 percent for the period from 2006 - 2011. Also, for the first time period, if a parcel is a mile from the nearest city center it is 2 percent less likely to change land use with additional decreases for each mile. This percentage decreases to 0.1 percent for the second time period. The other distance variables show that if a parcel is located a mile from a water feature it is 0.2 percent more likely to change land use and will increase for each additional mile. This percentage drops to less than 1 percent for the second period.

Table 5 Marginal Effect for Outcome 1 for All Multinomial Logits (Models 1 3)

\begin{tabular}{lccccccc} 
& \multicolumn{3}{c}{ Model 1 } & \multicolumn{3}{c}{ Model 2 } & \multicolumn{3}{c}{ Model 3 } \\
\cline { 2 - 7 } & $\beta$ & sig & $\beta$ & sig & $\beta$ & sig \\
\hline County $^{\wedge}$ & 0.085895 & $* * *$ & 0.083732 & $* * *$ & 0.003798 & $* * *$ \\
Impact Area & - & - & - & - & -0.00067 & - \\
Parcel Size & -0.04713 & $* * *$ & -0.04453 & $* * *$ & -0.00108 & $* * *$ \\
Distance to Nearest City & $-5.44 \mathrm{E}-06$ & $* * *$ & $-5.11 \mathrm{E}-06$ & $* * *$ & $-3.16 \mathrm{E}-07$ & $* * *$ \\
Distance to Water Feature & $7.75 \mathrm{E}-07$ & $* * *$ & $7.31 \mathrm{E}-07$ & $* * *$ & $3.57 \mathrm{E}-08$ & $* * *$ \\
Pop. Density & 0.000125 & $* * *$ & 0.00012 & $* * *$ & $1.42 \mathrm{E}-06$ & $* * *$ \\
& & & & & & \\
\hline$* * *=$ Significant at 1\% & $* *=$ Significant at 5\% & $*=$ Significant at 10\% & $\wedge$ = Dummy Variable
\end{tabular}

Table 6 shows the results for the logit estimations for Models $4-6$. These models use the RDD dataset and provide a stronger causal connection between the dependent variable outcomes and the drivers. The results for Models $4-6$ are very similar to those for Models $1-3$. For instance, the county variable is positive and significant for each model. The impact area variable is negative but insignificant. The directions of the other independent variables are the same as those for Models $1-3$. That is, a parcel that is small and near a city center is more likely to change land use. This likelihood increases as the population for the area increases and if the parcel is far from a water feature. These results hold across all the models with the exception of the latter two variables for Model 
6. In Model 6, the results show that as population increases, a parcel is less likely to change land use. For the distance to water feature variable, the result is insignificant.

Table 6 Results for Binary Logit for All Periods (Models 4 - 6)

\begin{tabular}{|c|c|c|c|c|c|c|}
\hline & \multicolumn{2}{|l|}{ Model 4} & \multicolumn{2}{|l|}{ Model 5} & \multicolumn{2}{|l|}{ Model 6} \\
\hline & $\beta$ & sig & $\beta$ & $\operatorname{sig}$ & $\beta$ & $\operatorname{sig}$ \\
\hline County $^{\wedge}$ & 1.032414 & $* * *$ & 1.032414 & $* * *$ & 3.248898 & $* * *$ \\
\hline Impact Area $^{\wedge}$ & - & - & - & - & -0.99331 & - \\
\hline Parcel Size & -0.59769 & $* * *$ & -0.59769 & $* * *$ & $-5.64 \mathrm{E}-01$ & $* * *$ \\
\hline Distance to Nearest City & $-8.6 \mathrm{E}-05$ & $* * *$ & $-8.6 \mathrm{E}-05$ & $* * *$ & $-1.25 \mathrm{E}-04$ & $* * *$ \\
\hline Distance to Water Feature & $-7.4 \mathrm{E}-05$ & $* * *$ & $-7.4 \mathrm{E}-05$ & $* * *$ & $-2.9 \mathrm{E}-05$ & - \\
\hline Pop. Density & 0.002764 & $* * *$ & 0.002764 & $* * *$ & -0.01507 & $* * *$ \\
\hline Constant & 1.23412 & $* * *$ & 1.23412 & $* * *$ & -1.18581 & - \\
\hline Pseudo R2 & 0.42 & & 0.41 & & 0.32 & \\
\hline $\mathrm{N}$ & 7821 & & 7821 & & 6369 & \\
\hline$* * *=$ Significant at $1 \%$ & $* *=$ Signific & nt at $5 \%$ & $*=$ Significa & $t$ at $10 \%$ & $\wedge=$ Dummy V & riable \\
\hline
\end{tabular}

Table 7 shows the marginal effects for Models $4-6$ logit estimations. There are two differences between the marginal effects for the first set of Models $(1-3)$ and the second (4-6). First, the magnitude of the marginal effects for Models $4-6$ are smaller than those for Models $1-3$. For instance, the marginal effects for the county variable for the first period (Model 2, Model 5) drop from 8 percent to 5 percent. The second difference is the number of significant coefficients between the models that examine the 2006 - 2011 period (Model 3, Model 6). For instance, all the coefficients for Model 6 drop in significance with the distance to water feature dropping below the 10 percent level. The next section summarizes and discusses the results. 
Table 7 Marginal Effects for All Binary Logits (Models 4-6)

\begin{tabular}{lccccccc} 
& \multicolumn{3}{c}{ Model 4 } & \multicolumn{3}{c}{ Model 5 } & \multicolumn{3}{c}{ Model 6 } \\
\cline { 2 - 7 } & $\beta$ & sig & $\beta$ & sig & $\beta$ & sig \\
\hline County^ $^{\wedge}$ & 0.050431 & $* * *$ & 0.050431 & $* * *$ & 0.002413 & $*$ \\
Impact Area^ & - & - & - & - & -0.00034 & - \\
Parcel Size & -0.02847 & $* * *$ & -0.02847 & $* * *$ & -0.00024 & $*$ \\
Distance to Nearest City & $-4.12 \mathrm{E}-06$ & $* * *$ & $-4.12 \mathrm{E}-06$ & $* * *$ & $-5.23 \mathrm{E}-08$ & $* *$ \\
Distance to Water Feature & $-3.53 \mathrm{E}-06$ & $* * *$ & $-3.53 \mathrm{E}-06$ & $* * *$ & $-1.20 \mathrm{E}-08$ & - \\
Pop. Density & 0.000132 & $* * *$ & 0.000132 & $* * *$ & $-6.28 \mathrm{E}-06$ & $*$ \\
& & & & & & \\
\hline$* * *=$ Significant at $1 \%$ & $* *=$ Significant at $5 \%$ & $*=$ Significant at $10 \%$ & $\wedge=$ Dummy Variable
\end{tabular}

\section{Discussion}

The previous section analyzes the drivers of land use change in the Treasure Valley across three periods: 2001 - 2011, 2001 - 2006 and 2006 - 2011. During the last period, Ada County implemented aspects of the Blueprint. In particular, it set out to encourage development within the city impact area and to discourage development in unincorporated and rural areas. This attempt to control land use in Ada County was not matched by the other Treasure Valley county, Canyon County. This difference in land use policy implementation introduced a natural experiment in which parcels that are nearly matching in many respects are unequally subjected to a single variable, in this case, the land use policies of Ada County. Given this scenario, two hypothesized outcomes are given. First, a parcel located in Ada County is less likely to change than if it was located within Canyon County for the period from 2006 - 2011. If this hypothesis is shown to be false, then the second hypothesis suggests that if a parcel is located in Ada County it is more likely to change from undeveloped to a developed land use if it is located within a designated city impact area for the same period. 
The results of the analysis do not show conclusive support for the either hypothesized outcome. The first hypothesis suggested that the coefficient for the county variable will be negative. The results show that for each model the county variable was positive for the period from 2006 - 2011. The variable is significant for Outcome 1 in Model 3 and is significant for Model 6. These results suggest that the Ada County government did not completely discourage land use change within Ada County. The second hypothesized outcome suggests that if the county variable is positive then the impact area variable will also be positive and have a larger effect than the county variable for the period in which aspects of the Blueprint are implemented (2006 - 2011). However, in the models that examined this time period (Model 3 and Model 6), the impact area variable was consistently found to be insignificant. These results suggest that the implementation of aspects of the Blueprint through the comprehensive plan of Ada County is not a driver of land use change. Ada County's ineffectiveness in steering land use change also suggest that counties that fit Lewis's (1996) second pattern of local government scope and arrangement do not have a substantial amount of control over local land use.

Although the treatment variables are shown to not have a large effect on the probability of parcel changing land use, the other independent variables are shown to have some explanatory power. The parcel size variable was significant for all models and suggests that this variable has the most explanatory power when it comes to explaining when a parcel will change land use. This variable is also negative for each outcome. This result suggests the larger the parcel, the less likely that it will change use. Another strong indicator of land use change is distance to the nearest city. The coefficient is significant 
for all outcomes and negative. This result indicates that a parcel is less likely to change land as the distance from the nearest city increases. The remaining independent variables are significant across all the models with the exception of the distance to water feature model. However, they do not have as large an effect on the probability of a parcel changing land use.

There are two important factors that could have contributed to the outcome of the present research. Investigating these factors should be considered the next step in researching the relationship between county governments and land use change. One perspective to consider is the degree of political fragmentation that exists in the Treasure Valley. As discussed above, Lewis (1996) argues that higher degrees of political fragmentation that exists within a given area are more likely to lead to land use change in the form of urban sprawl. Levels of fragmentation are deduced from the number of governments that have the ability to control and implement land use policy in a given area. The more government bodies that control land use policy, the higher level of urban sprawl. This is the case because the government bodies compete for tax money and, in order to attract developers, the governments are inclined to be more lenient towards enforcing land use policy. To measure the level of political fragmentation Lewis devised a political fragmentation index that was the product of total expenditure per capita by land use related local governments and the sum of squares of the percentages of the total expenditure accounted for each government. The sum of squares of the percentages is meant to capture, "the probability that two randomly selected dollars of local public expenditure in a given metro area were not spent by the same local government," (p. 49, italics original). The index and the level of fragmentation are expected to move in the 
same direction. Higher levels of fragmentation are represented as a higher number in the index.

Political fragmentation is a possibility in the Treasure Valley because of the number of local governments that are responsible for implementing land use policy. The Blueprint stated that the effort to control sprawl would be coordinated between county government in Ada County and the city governments within Ada County. However, implementation and enforcement were still the responsibility of the individual governments. This arrangement of land use regulation responsibilities seems to fit Lewis's concept of political fragmentation. However, the political fragmentation index could not be calculated for the Treasure Valley due to the lack of publicly available data for the years under investigation. The calculation of this index is important for future land use change research.

Another factor that could have possibly contributed to the ineffectiveness of Ada County in driving land use is the Great Recession in 2008. This seems like a likely factor given the dramatic decrease in the amount of land use development for the two periods. Table 1 showed that 24 percent of the parcels changed land use from 2001 to 2006 . This figure drops to 1 percent for the period ranging from 2006 to 2011. There is some research that exists that examines the link between the Great Recession and land use change. Wilson and Brown (2015), for instance, found in their study of southeastern Michigan, that the Great Recession reduced the difference in the rate and pattern of land cover change across communities with different socio-economic compositions. The authors attribute this result to both a decrease in investment into development from the private sector and infrastructure from the public sector. Kane et al. (2014), find in their 
study of Phoenix that much of the reduction in the development occurred largely in areas that experience mostly agricultural conversion and previously fast-growing areas. The explanation for the connection between land use change policy implementation and the Great Recession could be that in order to encourage development in the Treasure Valley, local governments, including the government for Ada County, created more allowances for developers.

\section{Conclusion}

Land use change is a global phenomenon that has a substantial, and often times, harmful, impact on ecological functions and environmental services. Land use change demonstrates the link between humans and the environment and is studied both by the natural and social sciences. Part of this research studies the socioeconomic drivers of land use change and the regulatory tools used to mitigate the impacts of these drivers. The regulatory tools that are often used are zoning and adequate facility provision ordinances. These tools are used at all levels of government, especially the local government bodies.

The present research looks at the effect that land use regulation implemented at the county level has on controlling land use change. The county government that is studied in this article is the Ada County government in Idaho. The Ada County government is used in this study because it presents the possibility of a natural experiment. The Boise Metro is a rapidly urbanizing area that spans Ada County and the bordering Canyon County. Ada County provides an opportunity for a natural experiment because Ada County and Canyon County have differing policies when it comes to land use change. In particular, Ada County, in 2007, implemented aspects of the Blueprint policies which encouraged 
urban development to occur within city impact areas and to discourage development in rural and unincorporated areas.

To determine if the county level government is effective in driving land use change, an RDD is used to improve the strength of the results in providing support for causal claims. The RDD takes a subset of a larger dataset in which observations are nearly matching except for a single variable. This difference based on a single variable effectively separates the dataset into two groups (control group and treatment group) with treatment being the differentiating variable.

Six models use three subsets based on the RDD and the entire dataset and are separated into three periods: 2001 - 2006, 2001 - 2006 and 2006 to 2011. The models are then estimated using a multinomial and binary logistic regressions. The results show that Ada County government did not have an effect on land use change. The coefficient for the city impact area is insignificant for the period in which Ada County implemented aspects of the Blueprint (2006 -2011). Also, the county variable was positive which indicated that development occurred within Ada County but location of the development was not driven by the location of the impact area. These results suggest that counties that share land use regulation responsibilities with many municipalities do not exercise effective control over land use change. 


\section{REFERENCES}

Ada County Comprehensive Plan. 2007. Accessed February 2017 from: https://adacounty.id.gov/Portals/0/DVS/PLN/Doc/ADA\%20COMP\%20PLAN\%2 OCOMPLETE.pdf

Alberti, Marina. 2005. "The effects of urban patterns on ecosystem function." International Regional Science Review. 28(2): 651 - 192.

Alonso, William. 1964. Location and Land Use. Cambridge MA: Harvard University Press.

Bengston, David N., Jennifer O. Fletcher, and Kristen C. Nelson. 2004. "Public policies for managing urban growth and protecting open space: policy instruments and lessons learned in the United States." Landscape and Planning. 69: 271 - 286.

Berk, Richard A. 1991. "Toward a Methodology for Mere Mortals.” Sociological Methodology, 21: 315 - 324.

Blalock, Hubert M. 1991. "Are there really any constructive alternatives to causal modeling?" Sociological Methodology. 21: 325 - 335.

Bockstael, Nancy E. 1996. "Modeling economics and ecology: The importance of a spatial perspective." American Journal Agricultural Economics. 78 (December): $1168-1180$.

Bockstael, Nancy E. and Elena G. Irwin. 2001. "Economics and the land use environment link." In The International Yearbook of Environmental and Resource Economics 2000/2001, eds. Tom Tietenberg and Henk Folmer. Cheltenham, UK: Edward Elgar, $1-54$. 
Blueprint for Good Growth. 2017. "Events.” Accessed March 2017 from:

https://web.archive.org/web/20050212075348/http://blueprintforgoodgrowth.com/ Events.asp.

Brawer, Judi and Matthew Vespa. 2008. "Thinking globally, acting locally: The role of local government in minimizing greenhouse gas emissions from new development." Idaho Law Review. 44(589): 1 - 48.

Butsic, Van, David J. Lewis and Lindsay Ludwig. 2011. “An econometrics analysis of land development with endogenous zoning." Land Economics. 87 (3): 412 - 432.

Carrion - Flores, Carmen and Elena G. Irwin. 2004. "Determinants of residential landuse conversion and sprawl at the rural-urban fringe." American Journal of Agricultural Economics, 86 (4): 889 - 904.

Carrion - Flores, Carmen and Elena G. Irwin. 2005. "Using Regression Discontinuity Design to Identify the Effect of Zoning on Rural Land Conversion.” Prepared for American Agricultural Economics Association Annual Meeting.

Dahal, Khila R., Shawn Benner and Eric Lindquist. 2017. "Urban hypothesis and spatiotemporal characterization of urban growth in the Treasure Valley, USA.” Applied Geography. 79: $11-25$.

DeFries, Ruth S., Gregory P. Asner and Richard A Houghton. 2004. Ecosystems and Land Use Change. Washington, DC: American Geophysical Union.

Freedman, David A. 1991. "Statistical Models and Shoe Leather.” Sociological Methodology. 21: $291-313$.

Fry, Joyce A., George Xian, Suming Jin, Jon A. Dewitz, Collin G. Homer, Limin Yang, Christopher A. Barnes, Nathaniel D. Herold and James D. Wickham. 2011. "Completion of the 2006 National Land Cover Database for the Conterminous United States.” Photogrammetric Engineering and Remote Sensing, 77(9): 858 864.

Fragkias, Michail and Jacqueline Geoghegan. 2010. "Commercial and industrial land use change, job decentralization and growth controls: a spatially explicit analysis." Journal of Land Use Science. 5(1): 45 - 66. 
Geoghegan, Jacqueline and Nancy E. Bockstael. 2003. "Testing for the effects of growth control measures using quasi-experimental design." Presented at the AERE Workshop "Spatial Theory, Modeling and Econometrics in Environmental and Resource Economics"

Grout, Cyrus A., William K Jaeger and Andrew J. Plantinga. 2011. "Land-use regulation and property values in Portland, Oregon: A regression discontinuity design approach.” Regional Science and Urban Economics. 41: 98 - 107.

Homer, Collin, Jon Dewitz, Joyce Fry, Michael Coan, Nazmul Hossain, Charles Larson, Nate Herold, Alexa McKerrow, J. Mick VanDreil, and James Wickham. 2007. "Completion of the 2001 National Land Cover Database for the Conterminous United States.” Photogrammetric Engineer and Remote Sensing, 73(4): 337 341.

Homer, Collin, Jon Dewitzs, Limin Yang, Suming Lin, Patrick Danielson, George Xian, John Coulston, Nathaniel Herold, James Wickham, and Kevin Megown. 2015. "Completion of the 2011 national land cover database for the conterminous United States - Representing a decade of land cover change information. Photogrammetric Engineering and Remote Sensing, 81(5): 345 - 354.

Irwin, Elena G. and Nancy E. Bockstael. 2002. "Interacting agents, spatial externalities and the evolution of residential land use patterns." Journal of Economics Geography. 2: $31-54$.

Irwin, Elena G. and Jacqueline Geoghegan. 2001. "Theory, data, methods: developing spatially explicit economic models of land use change." Agriculture Ecosystems \& Environment. 85: $7-23$.

Kane, Kevin and Abigail M. York, Joseph Tuccillo, Lauren E. Gentile and Yun Ouyang. 2014. "Residential development during the Great Recession: a shifting focus in Phoenix, Arizona." Urban Geography. 35 (4): 486 - 507.

Lee, David s. and Thomas Lemieux. 2010. "Regression discontinuity designs in economics." Journal of Economics Literature. 48(June): 281 - 355.

Levine, Jonathan. 2006. Zoned Out. Washington DC: Resources for the Future. 
Lewis, David J. and Ralph J. Alig. 2009. "Empirical methods for modeling landscape change, ecosystem services, and biodiversity." Western Economics Forum (Spring).

Lewis, Paul G. 1996. Shaping Suburbia. Pittsburgh: University of Pittsburgh University.

Li, Junxiang, Cheng Li, Feige Zhu, Conghe Song, and Jiangup Wu. 2013.

"Spatiotemporal pattern of urbanization in Shanghai, China between 1989 and 2005.” Landscape Ecology. 28: 1545 - 1565.

Munroe, Darla K., Cynthia Croissant and Abigail M. York. 2005. "Land use policy and landscape fragmentation in an urbanizing region: Assessing the impact of zoning." Applied Geography. 25: 121 - 141.

Muth, Richard F. 1969. Cities and Housing. Chicago: University of Chicago Press

Mills, Edwin S.1967. "An aggregative model of resource allocation in a metropolitan area.” American Economic Review, 57: 197 - 210.

Peterson, Jeffrey M., Marcellus M. Caldas, Jason S. Bergtold, Belinda S. Sturm, Russel W. Graves, Dietrich Earnhart, Eric A. Hanley, J. Christopher Brown. 2014. "Economic linkages to changing landscapes." Environmental Management. 53: 55 $-66$.

Planning Works and Paul, Hasting, Janofsky and Walker. 2006. "Blueprint for Good Growth.” Accessed February 2017 from: http://www.blueprintforgoodgrowth.com/Downloads.asp.

Thistlethwaite, Donald L. and Donald T. Campbell. 1960. "Regression - discontinuity analysis: An alternative to the ex post facto experiment." The Journal of Educational Psychology. 51(6): 309 - 317.

US Census (United States Census Bureau). 2014. State and county QuickFacts: Data derived from population estimates, American community survey, Census of population and housing, county business patterns, economic census, survey of business owners, building permits, Census of governments. Obtained September 24, 2014 from: http//quickfacts.census.gov/qfd/states/16000.html. 
US Census (United States Census Bureau). 2015. American Community Survey 5 - Year Estimates - Geodatabase Format. Obtained February 23 from: https://www.census.gov/geo/maps-data/data/tiger-data.html

Veldkamp, A. and E.F. Lambin. 2001. "Predicting land - use change.” Agriculture Ecosystems \& Environment. 85: $1-6$.

Wilson, Courtney R. and Daniel G. Brown. 2015. "Change in visible impervious surface area in southeastern Michigan before and after the 'Great Recession:' Spatial differentiation in remotely sensed land-cover dynamics." Population Environment 36: $331-355$ 
APPENDIX 
The additional variables in the alternative specification (AS) include a parcel's distance to the nearest highway and the median income of the area in which the parcel is located. Each alternative specification uses the categorical variable that captures land use change for the period from $2001-2011$ and the associated dataset.

\section{Table 8 Correlations of Independent Variables}

\begin{tabular}{|c|c|c|c|c|c|c|c|}
\hline County & $\begin{array}{c}\text { Impact } \\
\text { Area }\end{array}$ & $\begin{array}{c}\text { Parcel } \\
\text { Size }\end{array}$ & $\begin{array}{c}\text { Distance } \\
\text { to } \\
\text { Nearest }\end{array}$ & $\begin{array}{c}\text { Distance } \\
\text { to Water } \\
\text { Feature }\end{array}$ & $\begin{array}{l}\text { Distance } \\
\text { to } \\
\text { Highway }\end{array}$ & $\begin{array}{c}\text { Pop } \\
\text { Density }\end{array}$ & $\begin{array}{l}\text { Median } \\
\text { Income }\end{array}$ \\
\hline
\end{tabular}

\begin{tabular}{|c|c|c|c|c|c|c|c|c|}
\hline County & 1 & & & & & & & \\
\hline Impact Area & 0.7763 & 1 & & & & & & \\
\hline Parcel Size & -0.1244 & -0.3076 & 1 & & & & & \\
\hline $\begin{array}{l}\text { Distance to } \\
\text { Nearest City }\end{array}$ & -0.05 & -0.2958 & 0.42 & 1 & & & & \\
\hline $\begin{array}{l}\text { Distance to } \\
\text { Water } \\
\text { Feature }\end{array}$ & 0.2943 & -0.0445 & 0.0958 & 0.1931 & 1 & & & \\
\hline $\begin{array}{l}\text { Distance to } \\
\text { Highway }\end{array}$ & -0.025 & -0.1491 & 0.3 & 0.7672 & -0.0529 & 1 & & \\
\hline $\begin{array}{l}\text { Population } \\
\text { Density }\end{array}$ & 0.2314 & 0.3894 & -0.4031 & -0.4538 & -0.0606 & -0.3473 & 1 & \\
\hline $\begin{array}{l}\text { Median } \\
\text { Income }\end{array}$ & 0.2436 & 0.4003 & -0.3994 & -0.4467 & -0.0818 & -0.3442 & 0.9885 & 1 \\
\hline
\end{tabular}


Table 9 AS Results for Multinomial Logit including Distance to City and Median Income

\begin{tabular}{|c|c|c|c|c|c|c|}
\hline \multirow[t]{2}{*}{ Outcomes (Base: 0) } & \multicolumn{2}{|l|}{1} & \multicolumn{2}{|l|}{2} & \multicolumn{2}{|l|}{3} \\
\hline & $\beta$ & sig & $\beta$ & sig & $\beta$ & sig \\
\hline County $^{\wedge}$ & 0.808523 & $* * *$ & 1.432503 & $* * *$ & 1.537658 & $* * *$ \\
\hline Parcel Size & -0.46661 & $* * *$ & -0.53407 & $* * *$ & -0.51203 & $* * *$ \\
\hline Distance to Nearest City & $-5.5 \mathrm{E}-05$ & $* * *$ & $-7.2 \mathrm{E}-05$ & $* * *$ & $-7.6 \mathrm{E}-05$ & $* * *$ \\
\hline Distance to Water Feature & $8.85 \mathrm{E}-06$ & $* * *$ & $1.02 \mathrm{E}-05$ & $* * *$ & $-2.28 \mathrm{E}-06$ & - \\
\hline Median Income & 0.0032 & $* * *$ & 0.002474 & $* * *$ & 0.001968 & $* *$ \\
\hline Constant & -0.84916 & $* * *$ & -3.07152 & $* * *$ & -6.13324 & $* * *$ \\
\hline Pseudo R2 & 0.27 & & & & & \\
\hline $\mathrm{N}$ & 88943 & & & & & \\
\hline$* * *=$ Significant at $1 \%$ & $* *=$ Signific & $t$ at $5 \%$ & $*=$ Significan & at $10 \%$ & $\wedge=$ Dummy V & riable \\
\hline
\end{tabular}

Table 10 AS Results for Multinomial Logit including Distance to Highway and Population Density

Outcomes (Base: 0)

$\beta$

\begin{tabular}{lrrrrrr} 
& \multicolumn{1}{l}{$\beta$} & sig & $\beta$ & sig & \multicolumn{1}{l}{$\beta$} & \multicolumn{1}{l}{ sig } \\
\hline County^ & 0.944497 & $* * *$ & 1.785979 & $* * *$ & 1.98916 & $* * *$ \\
Parcel Size & -0.47844 & $* * *$ & -0.54854 & $* * *$ & -0.52929 & $* * *$ \\
Distance to Water & $-6.55 \mathrm{E}-$ & & & & & \\
Feature & 06 & $* * *$ & $-1.2 \mathrm{E}-05$ & $* * *$ & $-2.8 \mathrm{E}-05$ & $* * *$ \\
Distance to Highway & $-3.7 \mathrm{E}-05$ & $* * *$ & $-6.6 \mathrm{E}-05$ & $* * *$ & $-8 \mathrm{E}-05$ & $* * *$ \\
Pop. Density & 0.001624 & $* * *$ & 0.001299 & $* * *$ & 0.001143 & $* * *$ \\
Constant & -1.49592 & $* * *$ & -3.55303 & $* * *$ & -6.49936 & $* * *$ \\
& & & & & & \\
\hline
\end{tabular}

Pseudo R2

$\mathrm{N}$

$* * *=$ Significant at $1 \%$
0.26

88943

$* *=$ Significant at $5 \% \quad *=$ Significant at $10 \% \quad \wedge=$ Dummy Variable 
Table 11 AS Results for Multinomial Logit including Distance to Highway and Population Density

\begin{tabular}{lrrrrrr} 
Outcomes (Base: 0) & \multicolumn{2}{c}{1} & \multicolumn{2}{c}{2} & \multicolumn{2}{c}{3} \\
\cline { 2 - 7 } & $\beta$ & sig & $\beta$ & sig & $\beta$ & sig \\
\hline County^ & 0.929257 & $* * *$ & 1.772786 & $* * *$ & 1.998086 & $* * *$ \\
Parcel Size & -0.48546 & $* * *$ & -0.55529 & $* * *$ & -0.53851 & $* * *$ \\
Distance to Water & $-5.36 \mathrm{E}-$ & & & & & \\
Feature & 06 & $* * *$ & $-1.1 \mathrm{E}-05$ & $* * *$ & $-2.8 \mathrm{E}-05$ & $* * *$ \\
Distance to Highway & $-3.7 \mathrm{E}-05$ & $* * *$ & $-6.6 \mathrm{E}-05$ & $* * *$ & $-8.1 \mathrm{E}-05$ & $* * *$ \\
Median Income & 0.00434 & $* * *$ & 0.003542 & $* * *$ & 0.00295 & $* * *$ \\
Constant & -1.45725 & $* * *$ & -3.53875 & $* * *$ & -6.45626 & $* * *$ \\
& & & & & & \\
\hline Pseudo R2 & 0.25 & & & & & \\
$\mathrm{~N}$ & 88943 & & & & & \\
$* * *=$ Significant at 1\% & $* * *$ Significant at 5\% & $*=$ Significant at 10\% & $\wedge$ = Dummy Variable
\end{tabular}

